Discussion Paper 142

Institute for Empirical Macroeconomics

Federal Reserve Bank of Minneapolis

90 Hennepin Avenue

Minneapolis, Minnesota 55480-0291

August 2004

\title{
Search, Money, and Inflation under Private Information
}

\author{
Huberto M. Ennis* \\ Federal Reserve Bank of Richmond
}

\begin{abstract}
I study a version of the Lagos-Wright (2003) model of monetary exchange in which buyers have private information about their tastes and sellers make take-it-or-leave-it-offers (i.e., have the power to set prices and quantities). The introduction of imperfect information makes the existence of monetary equilibrium a more robust feature of the environment. In general, the model has a monetary steady state in which only a proportion of the agents hold money. Agents who do not hold money cannot participate in trade in the decentralized market. The proportion of agents holding money is endogenous and depends (negatively) on the level of expected inflation. As in Lagos and Wright's model, in equilibrium there is a positive welfare cost of expected inflation, but the origins of this cost are very different.
\end{abstract}

* huberto.ennis@rich.frb.org. Research Department, Federal Reserve Bank of Richmond, P.O. Box 27622, Richmond, Virginia 23261. Ph. (804) 697-8988. I thank Todd Keister, Randall Wright, the participants at the 2004 Summer Workshop on Money, Banking, and Payments at the Cleveland Fed, and seminar participants at the Minneapolis Fed for useful comments on a previous draft. I also benefited from patient discussions and comments from my colleagues at the Richmond Fed. The usual disclaimers apply. The views expressed here are those of the author and do not necessarily reflect those of the Federal Reserve Banks of Minneapolis, Richmond or the Federal Reserve System. 


\section{INTRODUCTION}

Lagos and Wright (2003) develop a search-theoretic model of money that is suitable for studying issues related to monetary policy and inflation. In previous contributions to this literature, the divisibility of money was difficult to handle because the models usually generated complicated dynamics of the distribution of money holdings. To avoid this problem, most of the work was done assuming indivisibility of money and limits on the amount of money that agents could carry. While this assumption increases the tractability of the models, it renders them unsuitable for the study of inflation. The paper of Lagos and Wright breaks with this trend in the literature by proposing an alternative set of assumptions. ${ }^{1}$ In particular, they assume that agents can hold any positive amount of divisible money, but they introduce a subperiod to the model where agents can trade, in a centralized market, goods for which they have quasilinear preferences. This new combination of assumptions makes the distribution of money holdings (endogenously) degenerate and hence makes policy analysis tractable. One crucial feature of the Lagos-Wright model is that in the interesting cases of the possible (steady state) monetary equilibria, the buyer in the decentralized market, when matched with an appropriate seller, must have some bargaining power that allows her to obtain a positive surplus from the match. When this is the case, the share of the surplus obtained by the buyer is positively associated with her money holdings and this extra payoff provides the incentives necessary for a positive demand for money even when, purely as an asset, money would have an insufficient real rate of return.

This feature of the Lagos-Wright model is shared with the previous money-search literature. In particular, if sellers have the power to propose prices and quantities and buyers can only decide whether or not to trade, most search models of money do not have a monetary equilibrium (see Curtis and Wright, 2003). This result follows from the fact that, by the time trading takes place, the buyer cannot adjust its money holdings and hence the sellers can extract all the surplus from trade. This is an instance of the classic hold-up problem in contract theory. One possibility to get away from the hold-up problem is to assume that sellers can commit to post prices ex ante and buyers can choose which market-post to attend. This is the strategy taken, for example, in Rocheteau and Wright (2004). An alternative possibility is to modify the information structure of the model. In particular, the ability of the seller to extract all the surplus from a match is a direct consequence of the fact that sellers have perfect information about the buyers' willingness to pay. More realistic information assumptions have been used in the literature, but again tractability

\footnotetext{
${ }^{1}$ There are other modifications of the standard model that have been used to deal with this problem. For example, Shi (1997). See Lagos and Wright (2003) for a discussion of the different approaches.
} 
limited results. In this paper I show that the Lagos-Wright framework can be use to study realistic information structures that bring new light in the nature of monetary exchange and the consequences of monetary policy.

My model is in many aspects very similar to that of Lagos and Wright (2003). The only important difference is in the treatment of the decentralized market activity. First, I assume that agents are ex ante heterogeneous with respect to their preferences for the goods that are being traded in that market: some agents are more likely to find the goods sold to them by a random seller very appealing. In other words, some agents tend to like the goods available in the decentralized market more than others. Second, upon entering a match, the buyer receives a preference shock that determines how much she actually likes the particular good being offered in that match. ${ }^{2}$ This shock is private information to the buyer and creates an additional level of (ex post) heterogeneity among agents. The ex ante heterogeneity is related to the likelihood of receiving a "favorable" preference shock after entering a match. Ex post, once agents are in a match, some will find out that they like the good being offered to them in the specific match very much. In that case, the agent obtains a positive surplus from the match in equilibrium. The third feature of my model that differs from the Lagos-Wright environment is that the seller has all the bargaining power in the decentralized market. Even though this is the case, the combination of ex post heterogeneity and private information makes a subgroup of the agents willing to hold money. Agents who are more likely to have a high marginal utility for the good sold in the decentralized market will carry positive money balances. Due to the existence of private information, they will then be able to extract a positive surplus whenever they enter a suitable match by using their holdings of money.

I show that there exists a monetary equilibrium where a proportion of the agents will hold a positive amount of money. Yet, as in Lagos and Wright's model, the distribution of money holdings will be very simple and easy to track in equilibrium. In particular, the distribution only has two mass points (zero and a positive number). ${ }^{3}$ More interestingly, not only is the positive mass-point endogenous (the intensive margin), but also the mass that the distribution puts in each point will depend on equilibrium outcomes (the extensive margin). ${ }^{4}$ For example, the level

\footnotetext{
${ }^{2}$ This is the kind of preference shocks used by Curtis and Wright (2003) to study (ex ante) price posting in the Trejos and Wright (1995) environment. Faig and Jerez (2003) study price posting under private information in Shi's (1997) environment. However, they use a central clearing mechanism to settle payments and hence no monetary issues arise in their analysis.

${ }^{3}$ Purely general equilibrium forces eliminate any price dispersion and all agents with money hold exactly the same amount and pay the same prices. This feature of the equilibrium significantly increases tractability and stands in contrast with some of the results in Curtis and Wright (2003).

${ }^{4}$ There are other papers using the Lagos-Wright approach that incorporate extensive margin effects. Rocheteau and Wright (2004) assume that $\alpha$, the probability of getting matched in the decentralized market, is a function
} 
of expected inflation in the economy will determine the proportion of agents that participate as potential buyers in the decentralized market and the amount of money that those agents take to that market. Since higher inflation rates discourage the use of money, fewer agents will decide to carry money to the decentralized market and even those that do will be able to buy lower quantities of the goods. These two factors create an endogenous welfare cost of inflation in the model that is associated with different factors than those studied in Lagos and Wright (2003). ${ }^{5}$

This paper achieves two main objectives. First, it provides a tractable analysis of the tradefrictions-based model of monetary exchange when there is private information about the willingness to pay by buyers. In this respect, it shows that inflation can result in welfare costs to society by reducing the participation of agents in those trades that are typically conducted through monetary exchange. Second, the paper shows that the existence of a monetary equilibrium in this kind of model is a more robust feature than suggested by the previous literature. In particular, under private information monetary exchanges still take place even if the sellers have all the power to set prices and quantities.

The paper is organized as follows. Section 2 provides the description of the environment, characterizes the monetary equilibrium in the model, and discusses the effects of positive expected inflation on equilibrium outcomes. Section 3 provides some quantitative estimates of the welfare cost of inflation in the model and section 4 concludes.

\section{THE MODEL}

The model is a modified version of that in Lagos and Wright (2003). Time is discrete and there is a continuum of infinitely lived agents with unit mass. Agents discount the future according to the discount factor $\beta \in(0,1)$. Each period is divided into two subperiods.

In the first subperiod, agents interact in a decentralized market where trade is anonymous and agents get matched in pairs. There are three possible situations in a particular meeting: either agent $j$ likes the goods that agent $k$ can produce, or agent $k$ likes the goods that agent $j$ can produce; or neither of the agents like what the other can produce. Each of the two possibilities for a single coincidence of wants meeting happens with probability $\sigma$ and the lack of coincidence of wants happens with probability $(1-2 \sigma)$. If agent $j$ likes what agent $k$ can produce, I will call $j$ the (potential) buyer and $k$ the seller. The buyer's utility is given by $\varepsilon_{i} u(q)$, where $q$ is the

of the number of participants in that market (see also Lagos and Rocheteau (2003)). The model in this paper, however, assumes a fixed value of $\alpha$.

${ }^{5}$ Faig and Jerez (2003) study directed (competitive) search in Shi's (1997) environment when buyers have private information about their willingness to pay for goods. They use a central clearing mechanism to settle payments and hence no monetary issues arise in their analysis. 
quantity consumed and $\varepsilon_{i} \in\left\{\varepsilon_{1}, \varepsilon_{2}\right\}$, with $\varepsilon_{1}>\varepsilon_{2}$. The seller's cost of production is given by $c(q)$ where $q$ is the quantity produced. The value of $\varepsilon_{i}$ is specific to the match and it is private information to the buyer. ${ }^{6}$ I will call agents with preference parameter $\varepsilon_{i}$ in a particular match as agents subtype $i$, with $i=1,2$. Agents are also heterogeneous with respect to the probability of being subtype $i$. I will say that an agent is of type $\xi$ if, upon entering a match as a buyer, the probability of her preferences being $\varepsilon_{1} u(q)$ is equal to $\xi \in[0,1]$. Types are also private information. Let $\Gamma(\xi)$ be the distribution of agents across different types.

In the second subperiod, agents interact in a centralized market and produce and consume a "general" good. Let $U(X)$ be the utility from consuming a quantity $X$ of the general good. These goods can be produced one-to-one with labor, from which agents experience linear disutility.

I maintain the technical assumptions from Lagos and Wright (2003). That is, $u, c$, and $U$ are twice continuously differentiable, $u(0)=c(0)=0, u^{\prime}>0, c^{\prime}>0, u^{\prime \prime}<0, c^{\prime \prime} \geq 0$, there exists $q_{i}^{*} \in(0, \infty)$ such that $\varepsilon_{i} u^{\prime}\left(q_{i}^{*}\right)=c^{\prime}\left(q_{i}^{*}\right)$ for $i=1,2, U^{\prime}>0, U^{\prime \prime} \leq 0$, and there exist $X^{*} \in(0, \infty)$ such that $U^{\prime}\left(X^{*}\right)=1$ and $U\left(X^{*}\right)>X^{*}$.

Finally, in this environment there is also an intrinsically useless, perfectly divisible and storable asset that will be called money. The stock of money in period $t=0,1, \ldots$ is given by $M_{t}$.

\subsection{The Sellers' Problem}

Upon entering a match, the buyer becomes one of the two possible subtypes. Then the seller makes a take-it-or-leave-it offer to the buyer, without knowing the buyer's subtype. ${ }^{7}$ The seller may want to choose a set of quantities and prices that voluntarily "separate" the two subtypes, that is, to set two price-quantity pairs such that a buyer chooses to buy one quantity at the given price if she is subtype 1 and the other quantity at the other price if she is subtype $2 .{ }^{8}$ Hence,

\footnotetext{
${ }^{6}$ Williamson and Wright (1994) first studied some of the potential effects of private information in a random matching model of money. Their environment is, however, very different than mine. They study an economy where there is no problem of absence of double coincidence of wants. Agents may choose to use money to facilitate trade because there is private information about the quality of the goods being traded. In contrast, in the model in this paper money is useful to circumvent an absence of double coincidence of wants problem, like in the traditional random matching models of money.

${ }^{7}$ Here we are assuming that the seller can observe the amount of money that the buyer has. Equivalently, if the seller cannot observe money holdings but can ask the buyer how much money she has before $\varepsilon_{i}$ is realized, then the buyer will have no incentives to lie and money holdings will be revealed. Before the realization of $\varepsilon_{i}$ the buyer is essentially in the same position as when money holdings were chosen. Hence, instead of lying the agent would choose to carry less money as long as carrying money is costly due to the inflation tax.

${ }^{8}$ Camera and Delacroix (2004) study a random matching non-monetary economy with private information over valuations of traded goods. Goods are indivisible in their model and there is only one good per match. This rules out any nonlinear pricing scheme like the ones studied here. However, under one of the trading mechanism studied by Camera and Delacroix, the seller separates different-type buyers by making a combination of sequential offers. This possibility is not studied there.
} 
the seller's offer is a price schedule $\left\{\left(q_{1}, d_{1}\right),\left(q_{2}, d_{2}\right)\right\}$, where $q_{i}$ is the quantity offered and $d_{i}$ the monetary payment required to buy that quantity.

To determine his best offer, the seller needs to have an estimate of the likelihood that the particular agent he is matched with is of subtype 1 or 2 . Let $p=\operatorname{Pr}\left[\varepsilon_{i}=\varepsilon_{1}\right]$ be such an estimate. In an equilibrium, this probability $p$ is endogenous and could be a function of the amount of money $m$ that the buyer carries into the match. In this subsection we will solve the seller's problem for all arbitrary combinations of $p$ and $m$. An equilibrium of the complete model is characterized in the next subsection. Given $p$ and $m$, the seller chooses a price schedule to maximize his expected surplus from the match. This problem is similar to a standard private information problem where the seller chooses prices and quantities to maximize expected surplus subject to the buyer's participation constraints and incentive compatibility constraints (see Maskin and Riley, 1984). There is, however, one important difference. The buyer enters the match with a given quantity of money balances $m$ and hence the seller can only demand from the buyer a monetary payment that is at most that amount. Both buyers and sellers take as given the value of money in the economy, $\phi$. The seller's problem is then, ${ }^{9}$

$$
\max _{\left(q_{1}, q_{2}, d_{1}, d_{2}\right)} p\left[-c\left(q_{1}\right)+\phi d_{1}\right]+(1-p)\left[-c\left(q_{2}\right)+\phi d_{2}\right]
$$

subject to

$$
\begin{array}{r}
q_{1}, q_{2} \geq 0, \quad d_{1} \leq m, \quad d_{2} \leq m, \\
\varepsilon_{1} u\left(q_{1}\right)-\phi d_{1} \geq 0, \quad \varepsilon_{2} u\left(q_{2}\right)-\phi d_{2} \geq 0, \\
\varepsilon_{1} u\left(q_{1}\right)-\phi d_{1} \geq \varepsilon_{1} u\left(q_{2}\right)-\phi d_{2}, \\
\varepsilon_{2} u\left(q_{2}\right)-\phi d_{2} \geq \varepsilon_{2} u\left(q_{1}\right)-\phi d_{1} .
\end{array}
$$

The first set of constraints are associated with feasibility. The second line of constraints are the participation constraints for the subtype 1 and 2 buyer, and the last two constraints are the incentive compatibility constraints for the subtype 1 and subtype 2 buyer, respectively.

\footnotetext{
${ }^{9}$ The payoff functions are a result of the environment. In subsection 2.2 it will become clear why in this environment the payoff for sellers and buyers in a match is linear in money balances which all agents value the same.
} 
Lemma 2.1. The solution to problem (1) satisfies:

(1) $\varepsilon_{1} u\left(q_{1}\right)-\phi d_{1} \geq 0$,

(2) $\varepsilon_{1} u\left(q_{1}\right)-\phi d_{1}=\varepsilon_{1} u\left(q_{2}\right)-\phi d_{2}$,

(3) $\varepsilon_{2} u\left(q_{2}\right)-\phi d_{2}=0$, and

(4) $d_{1} \geq d_{2}, q_{1} \geq q_{2}$.

These results are standard in the private information literature. The first result in the lemma tells us that subtype 2 agents will get zero surplus from trade. If this would not be the case, the seller could sell a smaller quantity at the same price while still having the subtype 2 agent participating in the trade. This move would clearly increase the seller's surplus. Using the first result and the incentive compatibility constraints we obtain the second result, which tells us that subtype 1 agents obtain a positive surplus from trade. The third result says that the incentive compatibility condition for subtype 1 agents must be binding in the solution to the problem. Otherwise the seller could increase his expected payoff without violating any of the constraint in the problem. Finally, the last result tells us that subtype 1 agents will be offered a quantity that is at least as big as that being offered to subtype 2 agents.

Let $z_{i}=\phi d_{i}$ and $z=\phi m$. Then, using the lemma, we can rewrite the seller's problem as follows:

$$
\max p\left[-c\left(q_{1}\right)+z_{1}\right]+(1-p)\left[-c\left(q_{2}\right)+\varepsilon_{2} u\left(q_{2}\right)\right]
$$

subject to

$$
\begin{gathered}
\varepsilon_{2} u\left(q_{2}\right) \leq z_{1} \leq z, \quad q_{1} \geq q_{2} \geq 0, \\
\varepsilon_{1} u\left(q_{1}\right)-z_{1}=\left(\varepsilon_{1}-\varepsilon_{2}\right) u\left(q_{2}\right), \\
\varepsilon_{2} u\left(q_{1}\right)-z_{1} \leq 0 .
\end{gathered}
$$

I characterize the solution to this problem in three stages. First, I study the case when money holdings are not binding $\left(z_{i}<z\right.$, for $\left.i=1,2\right)$; then when money holdings are binding but agent subtype 1 buys more quantity of the good than agent subtype 2; and finally, when both agents buy the same amount of the good being offered in the match (see Figure 1). 


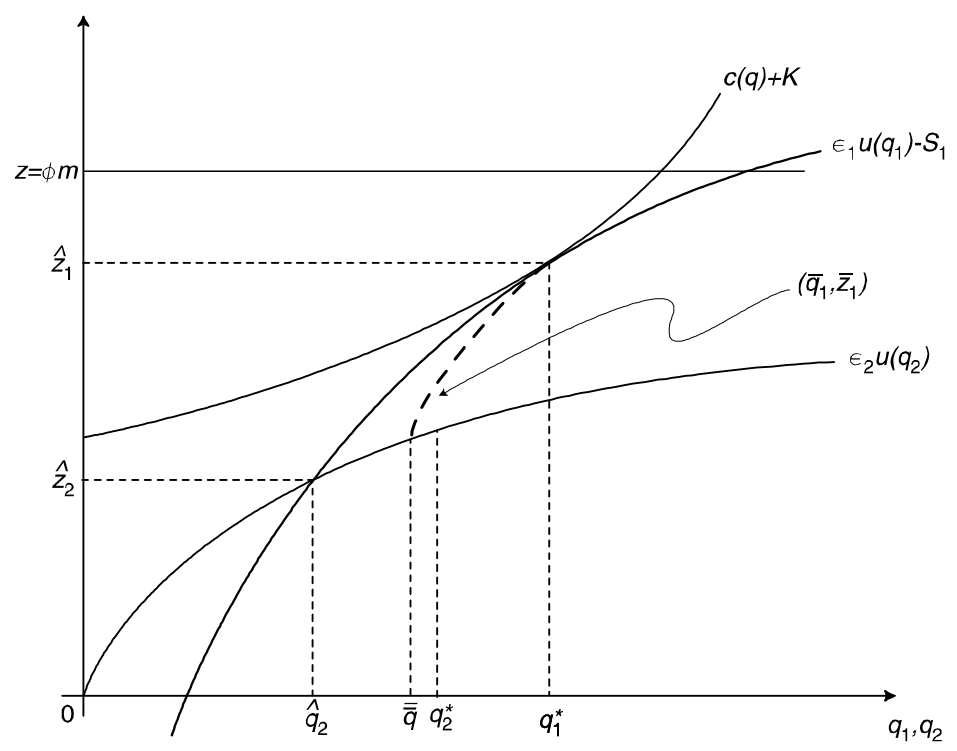

Figure 1

Define $\left(\widehat{q}_{1}, \widehat{q}_{2}, \widehat{z}_{1}\right)$ as the solution of problem (2) when we ignore the constraint $z_{1} \leq z$. Note that this solution is not a function of $z$. Then, there exist values of $z$ such that $\widehat{z}_{1} \leq z$ and the solution to the seller's problem is indeed $\left(\widehat{q}_{1}, \widehat{q}_{2}, \widehat{z}_{1}\right) .{ }^{10}$

Lemma 2.2. The solution $\left(\widehat{q}_{1}, \widehat{q}_{2}, \widehat{z}_{1}\right)$ to problem (2) when the money holdings constraint is non-binding is given by

$$
\begin{aligned}
\widehat{q}_{1} & =q_{1}^{*}, \\
c^{\prime}\left(\widehat{q}_{2}\right) & =\frac{1-p \frac{\varepsilon_{1}}{\varepsilon_{2}}}{1-p} \varepsilon_{2} u^{\prime}\left(\widehat{q}_{2}\right), \\
\widehat{z}_{1} & =\varepsilon_{2} u\left(\widehat{q}_{2}\right)+\varepsilon_{1}\left(u\left(\widehat{q}_{1}\right)-u\left(\widehat{q}_{2}\right)\right) .
\end{aligned}
$$

Recall that $q_{i}^{*}$ is such that $\varepsilon_{i} u^{\prime}\left(q_{i}^{*}\right)=c^{\prime}\left(q_{i}^{*}\right)$, for $i=1,2$. Note that since $1-p \frac{\varepsilon_{1}}{\varepsilon_{2}}<1-p$ we have that $\widehat{q}_{2}<q_{2}^{*}<q_{1}^{*}=\widehat{q}_{1}$. Also note that we can express this solution as a function of $p$, which will be determined in equilibrium. Define $S_{1} \equiv \varepsilon_{1} u\left(q_{1}\right)-z_{1}$ as the surplus of subtype 1 agents. Then, we have the following important result:

\footnotetext{
${ }^{10}$ Assume that $p \varepsilon_{1}<\varepsilon_{2}$ so that $\widehat{q}_{2}>0$. This condition needs to be checked in equilibrium and if not satisfied then $\widehat{q}_{2}$ would be zero in equilibrium.
} 
LEMma 2.3. If $\widehat{z}_{1} \leq z$ then the equilibrium surplus $S_{1}$ is only a function of $p$ (and not a function of $z$ ). Furthermore,

$$
\frac{d S_{1}(p)}{d p}<0
$$

Note also that

$$
\frac{d \widehat{q}_{2}}{d p}<0, \quad \frac{d \widehat{z}_{1}}{d p}>0, \text { and } \frac{d \widehat{z}_{2}}{d p}<0,
$$

where $\widehat{z}_{2}=\varepsilon_{2} u\left(\widehat{q}_{2}\right)$ is the real balances paid by subtype 2 agents to buy the quantity $\widehat{q}_{2}$.

Suppose now that $\widehat{z}_{1}>z$ so that $\left(\widehat{q}_{1}, \widehat{q}_{2}, \widehat{z}_{1}\right)$ is no longer the solution to the seller's problem. In particular, subtype 1 agents will spend all their money in the trade. However, subtype 2 agents may or may not spend all their money in the trade. Consider first the cases when they do not. Let us call this solution $\left(\bar{q}_{1}, \bar{q}_{2}, \bar{z}_{1}, \bar{z}_{2}\right)$ (see the dashed curve in Figure 1). Then, we have that $\bar{z}_{2}<\bar{z}_{1}=z$. From the first order conditions of problem (2) we have that $\left(\bar{q}_{1}, \bar{q}_{2}\right)$ must then solve the following system of equations:

$$
\begin{aligned}
f\left(\bar{q}_{2}, p\right) \varepsilon_{1} u^{\prime}\left(\bar{q}_{1}\right) & =p c^{\prime}\left(\bar{q}_{1}\right) \\
\varepsilon_{1} u\left(\bar{q}_{1}\right)-z & =\left(\varepsilon_{1}-\varepsilon_{2}\right) u\left(\bar{q}_{2}\right) \\
\bar{q}_{1} & \geq \bar{q}_{2}
\end{aligned}
$$

where $f\left(q_{2}, p\right) \equiv(1-p)\left[\varepsilon_{2} u^{\prime}\left(q_{2}\right)-c^{\prime}\left(q_{2}\right)\right] /\left(\varepsilon_{1}-\varepsilon_{2}\right) u^{\prime}\left(q_{2}\right)$. Note that $f$ is decreasing in $q_{2}$ and decreasing in $p$ for $q_{2}<q_{2}^{*}$. Also note that $\left(\widehat{q}_{1}, \widehat{q}_{2}\right)$ solve this system of equations when $z=\widehat{z}_{1}$. Then we have the following result:

Lemma 2.4. When $\bar{z}_{2}<\bar{z}_{1}=z<\widehat{z}_{1}$, the solution to problem (2), $\left(\bar{q}_{1}, \bar{q}_{2}, \bar{z}_{1}\right)$, is a function of $p$ and $z$ and satisfies:

(1) $\widehat{q}_{2}(p) \leq \bar{q}_{2}(z, p)<q_{2}^{*}$,

(2) $\bar{q}_{1}(z, p)<q_{1}^{*}$, and

(3) $\frac{d \bar{q}_{1}}{d p}<0, \frac{d \bar{q}_{1}}{d z}>0, \frac{d \bar{q}_{2}}{d p}<0, \frac{d \bar{q}_{2}}{d z}<0$.

The surplus obtained by subtype 1 agents is now not only a function of $p$ but also a function of $z$. In particular, it follows directly from the previous lemma that: 
Corollary 2.1. The trade surplus of subtype 1 buyers is $S_{1}(z, p) \geq S_{1}(p)$, with equality when $z=\widehat{z}_{1}$. Furthermore, we have that:

$$
\frac{d S_{1}(z, p)}{d p}<0, \quad \frac{d S_{1}(z, p)}{d z}<0
$$

We can now define $\overline{\bar{z}}$ as the value of real balances such that $\bar{z}_{2}(\overline{\bar{z}}, p)=\overline{\bar{z}}$, where $\bar{z}_{2}(z, p) \equiv$ $\varepsilon_{2} u\left(\bar{q}_{2}(z, p)\right)$. Since $q(\overline{\bar{z}})=\bar{q}_{1}(\overline{\bar{z}}, p)=\bar{q}_{2}(\overline{\bar{z}}, p) \equiv \overline{\bar{q}}(p)$ we have that

$$
c^{\prime}(q(\overline{\bar{z}}))=\frac{1-p}{1-p \frac{\varepsilon_{2}}{\varepsilon_{1}}} \varepsilon_{2} u^{\prime}(q(\overline{\bar{z}})) .
$$

It is clear then that $\overline{\bar{q}}(p)<q_{2}^{*}<q_{1}^{*}$. For any value of $z \leq \overline{\bar{z}}$ the solution to problem (2) has $z_{1}=z_{2}=z$ and $q_{1}=q_{2}=q(z)$ where $q(z)$ satisfies

$$
\varepsilon_{2} u(q(z))-z=0
$$

Finally note that $\overline{\bar{z}}$ is decreasing in $p$ and that, for all $z \leq \overline{\bar{z}}$, the surplus from trade obtained by subtype 1 agents is a linear, increasing function of $z$ (see Figure 2). The following proposition summarizes the previous findings.

Proposition 2.1. Given a probability $p$ that the buyer will be subtype 1 and an amount of real balances $z$ with which the buyer enters the match, the surplus for a buyer that turns out to be subtype 2 is zero and the surplus for a buyer that turns out to be subtype 1 is:

$$
S_{1}(z, p)= \begin{cases}\frac{\varepsilon_{1-} \varepsilon_{2}}{\varepsilon_{2}} z & \text { if } z \leq \overline{\bar{z}}(p), \\ \left(\varepsilon_{1}-\varepsilon_{2}\right) u\left(\bar{q}_{2}(z, p)\right) & \text { if } \overline{\bar{z}}(p)<z<\widehat{z}_{1}(p), \\ \left(\varepsilon_{1}-\varepsilon_{2}\right) u\left(\widehat{q}_{2}(p)\right) & \text { if } \widehat{z}_{1}(p)<z .\end{cases}
$$

With this surplus function describing the outcome in a prototypical match, we are now ready to study a (monetary) equilibrium of the overall economy.

\subsection{Monetary Equilibrium}

To describe a monetary equilibrium we start by studying the problem of an agent $\xi$ that enters the decentralized market with $z$ units of real balances and takes as given the seller's beliefs $p(z)$, the equilibrium distribution of (real) money holdings $F(\widetilde{z})$, and the value of money $\phi$. Let $V_{\xi}(z, s)$ be the value function for an agent $\xi$ in such a situation, where the state of the economy is given 


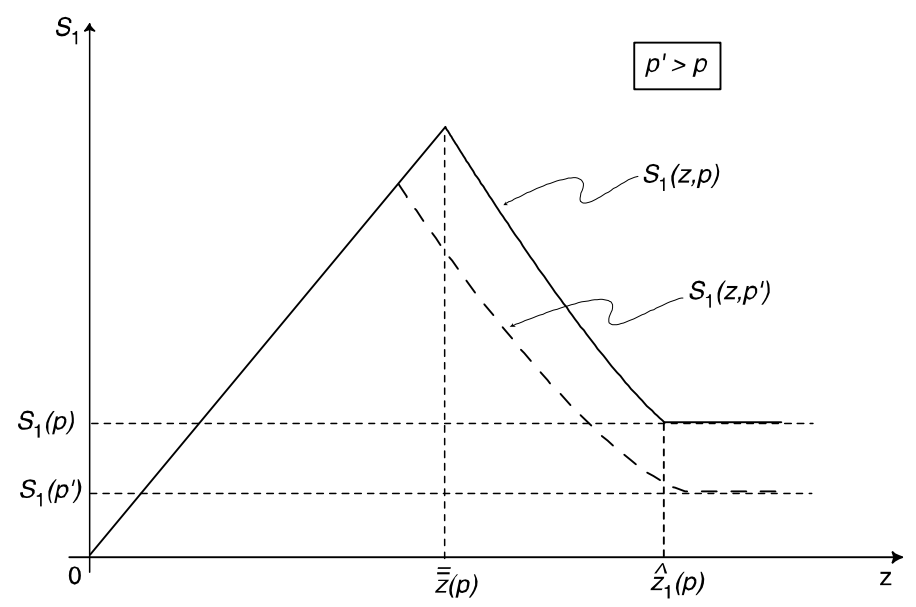

Figure 2

by $s=(p(z), F(\widetilde{z}), \phi)$. Also define $W_{\xi}(z, s)$ to be the value function for an agent entering the centralized market with $z$ units of real balances in state $s$. Notice that the amount of goods traded in a match does not depend on the real money holdings of the seller. Then, we have that:

$$
\begin{aligned}
V_{\xi}(z, s)= & \sigma\left\{E_{\xi}\left(\varepsilon_{i} u\left[q_{i}(z, p(z))\right]+W_{\xi}\left[z-z_{i}(z, p(z)), s\right]\right)\right\}+ \\
& \sigma \int E_{p(\widetilde{z})}\left(-c\left[q_{i}(\widetilde{z}, p(\widetilde{z}))\right]+W_{\xi}\left[z+z_{i}(\widetilde{z}, p(\widetilde{z})), s\right]\right) d F(\widetilde{z})+ \\
& (1-2 \sigma) W_{\xi}(z, s),
\end{aligned}
$$

where $E_{\xi}$ denotes the expectation over $\varepsilon_{i}, i=1,2$, for the probability distribution with parameter $\xi\left(=\operatorname{Pr}\left[\varepsilon_{i}=\varepsilon_{1}\right]\right)$, and $E_{p(\widetilde{z})}$ is the expectation over $\varepsilon_{i}$ for the probability distribution with parameter $p(\widetilde{z})$. Also, we have that:

$$
W_{\xi}(z, s)=\max \left\{U(X)-H+\beta V_{\xi}\left(z_{+1}, s_{+1}\right)\right\}
$$

subject to

$$
X=H+z-\frac{\phi}{\phi_{+1}} z_{+1},
$$

and an equilibrium law of motion for $s$ that is taken as given by the individual. From this expression for $W_{\xi}$ it is easy to see that in equilibrium $X=X^{*}, z_{+1}$ does not depend on $z$, and $W_{\xi}$ is linear in $z$. Recall here that $X^{*}$ is such that $U^{\prime}\left(X^{*}\right)=1$.

We know from the previous section that agents with a low preference for the good in a particular match (i.e., agents with $\varepsilon_{i}=\varepsilon_{2}$ ) get zero surplus from that match. ${ }^{11}$ Hence, we can rewrite the

\footnotetext{
${ }^{11}$ One possibility would be for the seller to try to separate the different types $\xi$ by offering some surplus to the agent with $\varepsilon_{i}=\varepsilon_{2}$. This contract would tend to attract agents with lower $\xi$, that is those with a higher probability
} 


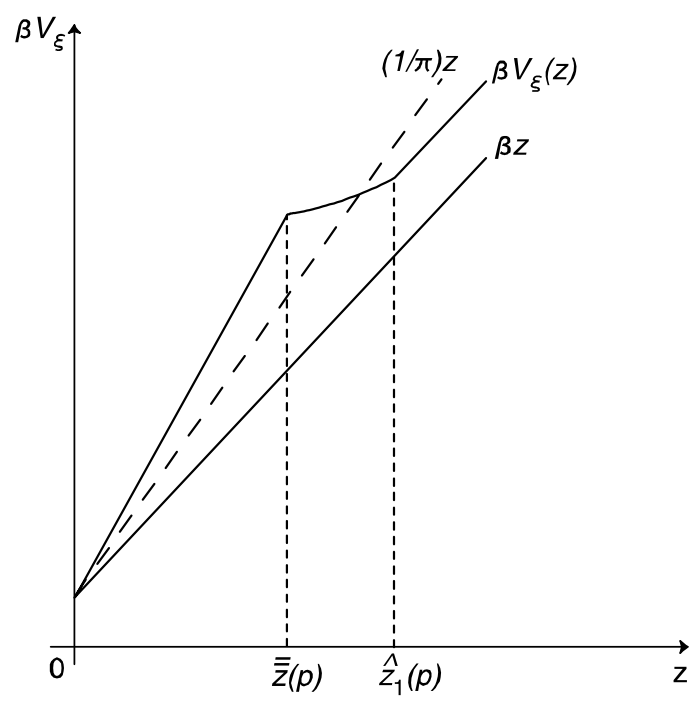

Figure 3

value function $V_{\xi}(z, s)$ as follows:

$$
V_{\xi}(z, s)=\sigma \xi S_{1}(z, p(z))+v(s)+z+\max _{z_{+1}}\left\{-\pi_{+1} z_{+1}+\beta V_{\xi}\left(z_{+1}, s_{+1}\right)\right\}
$$

where $v(s)=U\left(X^{*}\right)-X^{*}+\sigma \int E_{p(\widetilde{z})}\left(-c\left[q_{i}(\widetilde{z}, p(\widetilde{z}))\right]+z_{i}(\widetilde{z}, p(\widetilde{z}))\right) d F(\widetilde{z})$ and $\pi_{+1}=\phi / \phi_{+1}$ is the (gross) rate of inflation. Because the optimal choice of $z_{+2}$ does not depend on $z_{+1}$, we can find the optimal value of $z_{+1}$ by solving the following problem:

$$
\max _{z_{+1}}\left\{-\pi_{+1} z_{+1}+\beta z_{+1}+\beta \sigma \xi S_{1}\left(z_{+1}, p_{+1}\left(z_{+1}\right)\right)\right\}
$$

This is an economy with asymmetric information and we use the standard sequential equilibrium concept to identify possible outcomes. In particular, the next proposition shows that $p(z)=p$ (independent of $z$ ) is a set of beliefs consistent with a (robust) sequential equilibrium. Now, when $p_{+1}$ is independent of $z_{+1}$ in problem (4) the surplus function $S_{1}\left(z_{+1}, p_{+1}\right)$ is given by expression (3) and the solution is either $\overline{\bar{z}}\left(p_{+1}\right)$ or zero (see Figure 3 ).

We know that in any monetary equilibrium $\pi_{+1} \geq \beta$ (see Lagos and Wright (2003), Lemma 3). Let $\xi^{s}\left(\pi_{+1}\right)$ be such that

$$
\beta\left[\xi^{s} \sigma \frac{\varepsilon_{1}-\varepsilon_{2}}{\varepsilon_{2}}+1\right]=\pi_{+1}
$$

of having $\varepsilon_{i}=\varepsilon_{2}$. However, this type of scheme would require some commitment by the seller. Upon entering the match, after revealing the value of $z$ carried by the buyer, the seller's optimal contract is to give zero surplus to those agents with $\varepsilon_{i}=\varepsilon_{2}$. 
Then, agents with $\xi \geq \xi^{s}\left(\pi_{+1}\right)$ choose real balances $z_{+1}=\overline{\bar{z}}\left(p_{+1}\right)$ and agents with $\xi<\xi^{s}\left(\pi_{+1}\right)$ choose $z_{+1}=0$. For this reason, the equilibrium distribution of money holdings $F$ has only two mass-points, $\overline{\bar{z}}\left(p_{+1}\right)$ and 0 , and $\varphi=1-\Gamma\left(\xi^{s}\right)$ is the mass of agents holding positive real money balances. For simplicity, assume that the distribution of types is uniform; that is, assume that $\Gamma$ is a uniform distribution with support $(0,1)$. Then, conditional on meeting someone with money, the seller meets a subtype 1 agent with probability $p_{+1}$, which is computed using Bayes' rule and in equilibrium is given by:

$$
p_{+1}=\int_{\xi^{s}}^{1} \frac{\xi}{1-\xi^{s}} d \xi=\frac{1-\left(\xi^{s}\right)^{2}}{2\left(1-\xi^{s}\right)}=\frac{1+\xi^{s}}{2} .
$$

The following proposition fully characterizes this equilibrium.

Proposition 2.2. A sequence $\left\{\xi_{t}^{s}, p_{t}, q_{t}, z_{t}(\xi), \phi_{t}\right\}_{t=0}^{\infty}$ satisfying the following equations describes a monetary (sequential) perfect foresight equilibrium for this economy:

$$
\begin{aligned}
z_{t}(\xi) & =\overline{\bar{z}}\left(p_{t}\right) \text { for all } \xi \geq \xi_{t}^{s}=\frac{\varepsilon_{2}}{\sigma\left(\varepsilon_{1}-\varepsilon_{2}\right)}\left(\frac{\pi_{t+1}}{\beta}-1\right), \\
z_{t}(\xi) & =0 \text { for all } \xi<\xi_{t}^{s} \\
p_{t} & =\frac{1+\xi_{t-1}^{s}}{2} \\
q_{t} & =\overline{\bar{q}}\left(p_{t}\right) \text { for all } \xi \geq \xi_{t}^{s}, \text { and } \\
\phi_{t} & =z_{t}\left(1-\xi_{t-1}^{s}\right) / M_{t},
\end{aligned}
$$

where $\pi_{t+1}=\phi_{t} / \phi_{t+1}$ and $\xi_{t}^{s} \in[0,1]$ for all $t$.

It is interesting to note here that even though the general problem for the seller allows for different prices and quantities to be offered with the objective of "separating" the subtypes of buyers, in equilibrium only one combination of price and quantity is offered and observed. ${ }^{12}$

Also note that Bayesian updating on the equilibrium path determines a relevant restriction on the equilibrium belief function $p(z)=p$. For this reason there is a rational expectations element to this definition of equilibrium. Given the predicted inflation rate, agents anticipate that next-period sellers will use $p_{t+1}$ as their estimate of the probability of facing a buyer with $\varepsilon=\varepsilon_{1}$. Knowing this, agents with $\xi>\xi_{t}^{s}$ decide to hold $\overline{\bar{z}}\left(p_{t+1}\right)$ real balances to use in the decentralized market next period (this is the amount of real balances that allows them to maximize their expected surplus from an eventual match given that the sellers will be using $p_{t+1}$ as their estimated probability of $\varepsilon_{1}$ ). Then, the expectations over $p_{t+1}$ are fulfilled as long as the actual

\footnotetext{
${ }^{12}$ In consequence, we also have that in equilibrium $v(s)=U\left(X^{*}\right)-X^{*}+\sigma \varphi(-c(\overline{\bar{q}})+\overline{\bar{z}})$.
} 
$p_{t+1}$ equals $\left(1+\xi_{t}^{s}\right) / 2$, a function of the expected $p_{t+1}$. Similarly, actual inflation $\phi_{t} / \phi_{t+1}$ is a function of expected inflation (through the equilibrium determination of $\xi_{t}^{s}$ ) and they should be equalized in equilibrium.

Consider now the case when $M_{t}=M$ for all $t$. In this case, for a large enough value of $\varepsilon_{1}$, there exists a steady state monetary equilibrium with no inflation that solves the following equations:

$$
\begin{aligned}
\xi^{S S} & =\frac{\varepsilon_{2}}{\sigma\left(\varepsilon_{1}-\varepsilon_{2}\right)}\left(\frac{1}{\beta}-1\right), \\
p^{S S} & =\frac{1+\xi^{S S}}{2}, \\
c^{\prime}\left(q^{S S}\right) & =\frac{1-p^{S S}}{1-p^{S S} \frac{\varepsilon_{2}}{\varepsilon_{1}}} \varepsilon_{2} u^{\prime}\left(q^{S S}\right), \\
\phi^{S S} & =\varepsilon_{2} u\left(q^{S S}\right)\left(1-\xi^{S S}\right) / M .
\end{aligned}
$$

It is then straightforward to obtain the following comparative statics results:

Lemma 2.5. In a steady state monetary equilibrium with no inflation we have that:

$$
\text { (i) } \frac{\partial \xi^{S S}}{\partial \sigma}<0, \quad(i i) \frac{\partial p^{S S}}{\partial \sigma}<0, \quad(i i i) \frac{\partial q^{S S}}{\partial \sigma}>0, \text { and } \quad(i v) \frac{\partial \phi^{S S}}{\partial \sigma}>0 .
$$

The lemma shows that less frictions in the decentralized market (i.e., high values of $\sigma$ ) result in a steady state monetary equilibrium where $(i)$ a higher proportion of agents hold money; $(i i)$ it is less likely for a seller who has met a potential buyer to be facing a subtype 1 buyer; (iii) the quantities traded in a given match are higher; ${ }^{13}$ and $(i v)$ the value of money is higher (or in other words, the price level is lower). The comparative statics with respect to $\beta$ are the same.

Obviously, in this equilibrium money is neutral since $q^{S S}$ and $\xi^{S S}$ do not depend on $M$. Consider, for example, the case of $M^{\prime}=k M$, then we have that in equilibrium

$$
M^{\prime} \phi^{\prime}=\varepsilon_{2} u\left(q^{S S}\right)\left(1-\xi^{S S}\right)=M \phi^{S S}
$$

and hence $\phi^{\prime}=(1 / k) \phi^{S S}$. However, we show in the next subsection that in this economy money is not superneutral.

\footnotetext{
${ }^{13}$ This happens because when search frictions increase, agents decide to take to the decentralized market lower individual money holdings $\left(\partial z^{S S} / \partial \sigma>0\right)$. Once the agent enters the match with lower money holdings it is optimal for the seller to offer lower quantities. Agents carry lower money holdings anticipating that the seller will increase his estimate of the conditional probability of facing a subtype 1 agent (as less people participate in the market). If the agent were to carry the same amount of money as before, the seller would offer a higher quantity, but at a higher price (so that the extra benefit from the trade is not enough to compensate for the cost of holding those extra units of money) and would lower the surplus obtained by the agent if she happens to have $\varepsilon=\varepsilon_{1}$.
} 


\subsection{Changes in the Money Supply}

Suppose now that the money supply is growing at a constant rate $\tau$. Since in equilibrium not all agents hold money when they enter the decentralized market, we assume that monetary injections take place while agents are still in the centralized market. ${ }^{14}$ In this way, money gets redistributed among agents so that only those with high values of $\xi$ exit the centralized market with money.

We consider an equilibrium with a constant inflation rate; that is, $\phi_{t} / \phi_{t+1}=\pi$ for all $t$. Since the quantities traded are also constant, it is easy to show that in a monetary equilibrium $\pi=(1+\tau)$. Then, in such an equilibrium the proportion of agents not holding money is given by:

$$
\xi_{\tau}=\frac{\varepsilon_{2}}{\sigma\left(\varepsilon_{1}-\varepsilon_{2}\right)}\left(\frac{\pi}{\beta}-1\right),
$$

and for a high enough inflation rate we have that $\xi_{\tau}$ is greater than unity, no agent chooses to hold money, and there is no monetary equilibrium. Then, using Proposition (2.2) we obtain the following lemma:

LEMma 2.6. In the set of constant-inflation monetary equilibria indexed by $\tau$, if $\xi_{\tau}<1$, then we have that:

$$
\text { (i) } \frac{\partial \xi_{\tau}}{\partial \tau}>0, \quad(i i) \frac{\partial p_{\tau}}{\partial \tau}>0, \text { and } \quad(i i i) \frac{\partial q_{\tau}}{\partial \tau}<0 .
$$

The lemma tells us that in economies with higher levels of inflation, $(i)$ fewer agents hold money, (ii) it is more likely for a seller who has found a potential buyer to be facing a subtype 1 buyer, and (iii) the quantities traded in a given match are lower.

Since the quantities produced and traded in the centralized market do not change with inflation, it is clear that higher levels of inflation imply lower equilibrium welfare. This is the case for two reasons. First, in economies with higher inflation fewer agents hold money in the decentralized market, decreasing the number of matches where trade takes place (the extensive margin effect). Second, even in those matches where trade does take place, since each agent holds less money in equilibrium, the quantities traded in a given match are lower and the benefit from the match is reduced (the intensive margin effect).

Let us define the real interest rate in this economy as $r$ and the nominal interest rate as $i$. Then, we have that in equilibrium $1+r=1 / \beta$ and $1+i=\pi / \beta$. The optimal policy in

${ }^{14}$ Lagos and Wright (2003) assume that the monetary injections happen after agents leave the centralized markets. 
this economy is to set the nominal interest rate $i$ as low as possible, eventually to zero, as in the Friedman Rule. At that level, the threshold $\xi_{\tau}$ equals zero and all agents hold money. ${ }^{15}$ Then, we have that the equilibrium quantities traded are given by $\overline{\bar{q}}(1 / 2)<q_{1}^{*}$, away from the constrained optimum. This is an important feature of the present model that contrasts with the standard cash-in-advance model where the Friedman rule implements the social optimum. ${ }^{16}$

\section{THE WELFARE COST OF INFLATION}

In this section I use the model to provide some rough estimates of the welfare cost of inflation based on data for the US economy. In the calibration of parameter values, to facilitate comparisons, I follow as close as possible the strategy in Lagos and Wright (2003). Normalize $\varepsilon_{1}=1$ and $\varepsilon_{2}=\varepsilon<1$. The utility function for goods in the centralized market is $U(X)=B \log (X)$ and that for goods in the decentralized market is $u(q)=\left[(q+b)^{1-\eta}-b^{1-\eta}\right] /(1-\eta)$. Also assume that $c(q)=q$. From the equilibrium conditions in proposition (2.2) we then have that: ${ }^{17}$

$$
\begin{aligned}
\xi(i) & =\frac{\varepsilon}{\sigma(1-\varepsilon)} i, \\
p(i) & =\frac{1+\xi(i)}{2}, \\
q(i) & =\left[\frac{(1-p(i)) \varepsilon}{1-\varepsilon p(i)}\right]^{\frac{1}{\eta}}-b,
\end{aligned}
$$

and real money demand is $L(i)=\varepsilon u(q(i))(1-\xi(i))$. Total output per period, $Y(i)$, is the sum of the equilibrium output in the centralized market, $B$, and in the decentralized market, $\sigma(1-\xi(i)) q(i)$. We consider the case when $b \approx 0$ and hence we have four free parameters: $B, \sigma$, $\varepsilon$, and $\eta$.

Using annual data for the nominal interest rate on commercial paper and the ratio of $M_{1}$ to nominal GDP, we choose parameter values so as to minimize the sum of square errors between the observed levels of the money demand and those predicted by the model. Figure 4 shows the result for the 1900 - 2003 sample.

\footnotetext{
${ }^{15}$ The Friedman rule eliminates the inefficiency in the extensive margin but cannot eliminate the inefficiency in the intensive margin. At the time of choosing money holdings the agent anticipates the seller's incentive to hold-up and, as a response, carries less money. For a set of related results, see Rocheteau and Wright (2004).

${ }^{16}$ When $\varepsilon_{1}=\varepsilon_{2}$, there are a continuum of steady states monetary equilibria under the Friedman Rule. This feature is shared with the cash-in-advance economy (see Woodford, 1994, Proposition 1). However, since the buyer has no incentives to carry any specific amount of real balances, it is still possible that the equilibrium would be inefficient, i.e., $q<q^{*}$.

${ }^{17}$ We maintain the assumption that agents' types are uniformly distributed. Alternative assumptions about this distribution could help to fit the data better. We keep the uniform distribution assumption for the sake of parsimony.
} 


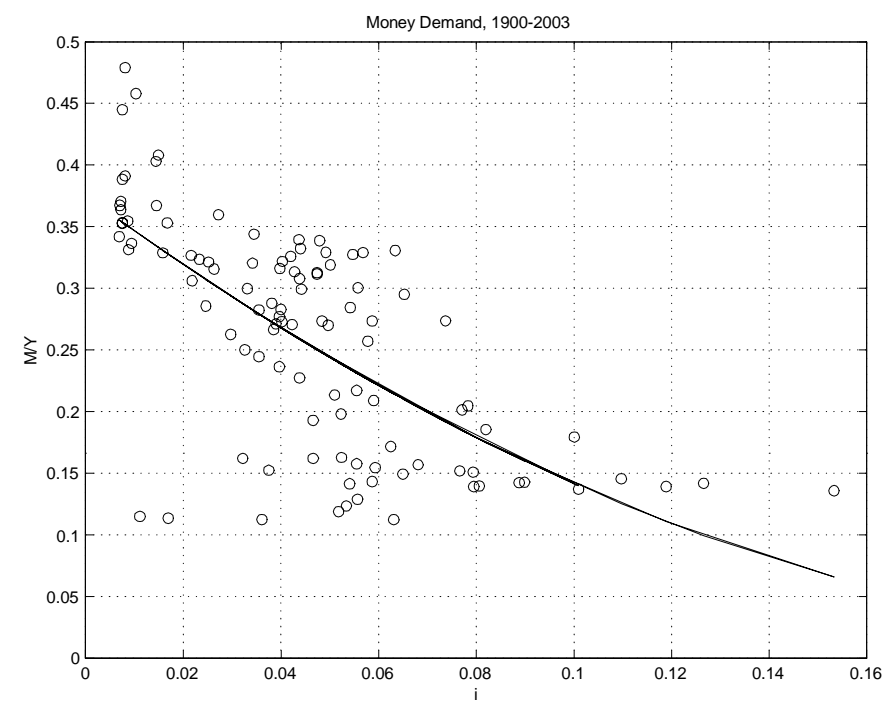

Figure 4

The model produces a reasonable fit. In the data there appears to be a lower bound in the level of monetization that the model seems to miss (especially at relatively high interest rates). Note that in the model, a sufficiently high, yet possibly observable, interest rate would make $\xi^{s}=1$ and hence drive the demand for money to zero, something that seems at odds with the data. ${ }^{18}$ Aside from this shortcoming, there is another important limitation of this kind of exercise. Specifically, the statistical relationship between money demand, output, and interest rates in the US has been quite unstable over the years (see, for example, Goldfeld and Sichel, 1990). Clearly, innovations like credit cards and other alternative means of payments have contributed significantly to this instability. Figure 5 shows that the model systematically underestimates the demand for money early in the sample period and systematically overestimates it late in the period. ${ }^{19}$

The estimated parameter values are not very precisely identified. The figures were constructed with the set of parameter values that best fit the data. However, there are several different combinations of parameter values that produce essentially the same fit. Different parameter values imply different welfare costs of inflation. For this reason, I provide the welfare calculations

\footnotetext{
${ }^{18}$ One could modify the model to introduce a very high third value of $\varepsilon$, say $\varepsilon_{3}$, and some agents with high probability of obtaining such a high level of utility from a match. In that case, these agents would be very reluctant to hold no money, even at relatively high interest rates. This modification can produce a lower bound in the aggregate demand of money for all potentially observable interest rates which would help the model to fit the data in Figure 4 better.

${ }^{19}$ The model generates large shorter-term fluctuations than those observed in the data. This is a standard feature on this kind of exercise. See Lucas (2000) for a discussion.
} 


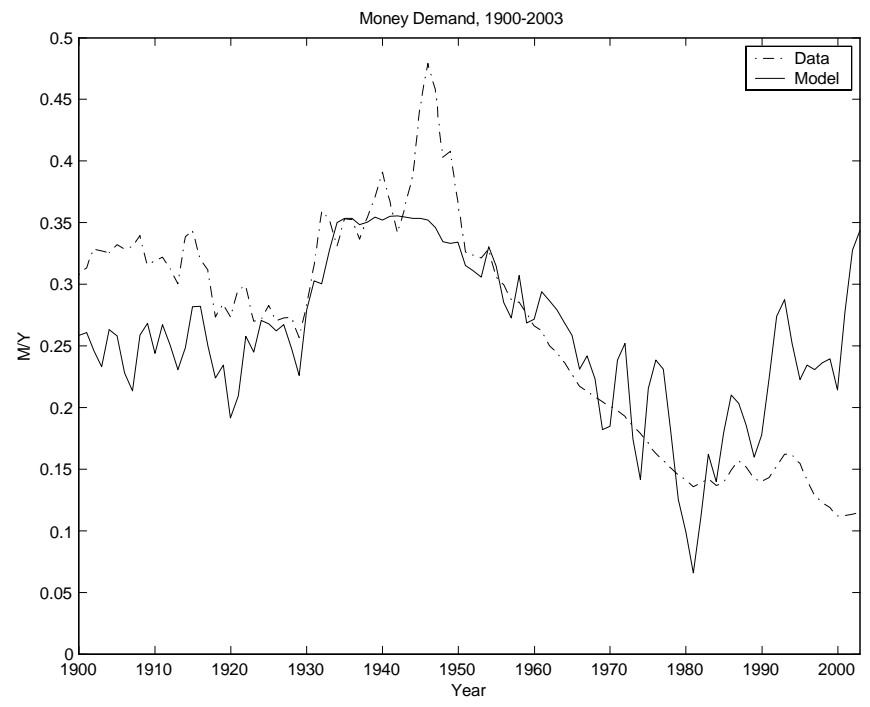

Figure 5

for the five combination of parameter values that produce the best fit of the data (all of them with an associated coefficient of determination differing in less than 0.001 from the others, see Table 1). ${ }^{20}$

Table 1

\begin{tabular}{c|ccccc}
\hline Parameters & $\eta$ & $B$ & $\sigma$ & $\varepsilon$ & $R^{2}$ \\
\hline 1 & 0.289 & 0.089 & 0.289 & 0.467 & 0.4734 \\
2 & 0.311 & 0.044 & 0.178 & 0.356 & 0.4734 \\
3 & 0.267 & 0.111 & 0.378 & 0.533 & 0.4732 \\
4 & 0.267 & 0.133 & 0.400 & 0.556 & 0.4728 \\
5 & 0.400 & 0.156 & 0.156 & 0.356 & 0.4725 \\
\hline
\end{tabular}

In equilibrium, all agents receive a real money transfer $T=\tau \phi_{t} M_{t}=\tau(1-\xi(i)) z(i)$ upon entering the centralized market. The equilibrium value for an agent of type $\xi \geq \xi(i)$ of being in the decentralized market at the start of the day (when the steady state nominal interest rate is i) is given by:

$$
(1-\beta) V_{\xi}(i)=\sigma \xi S_{1}(i)-\xi(i) \tau z(i)+v(i),
$$

${ }^{20}$ The search was done with a grid of size 44 for each parameter in the interval $[0,1]$. The value of $B$ does not have to be in the interval $[0,1]$ but unrestricted searches show that to fit the data $B$ has to be small (and certainly smaller than 1). For reference, the $R^{2}$ for a standard linear OLS regression was 0.4455 . 
where $v(i)=U\left(X^{*}\right)-X^{*}+\sigma(1-\xi(i))[-q(i)+\varepsilon u(q(i))], X^{*}=B$, and $S_{1}(i)=(1-\varepsilon) u(q(i))$. The second term in the right side of expression (5) is the cost (net of the money transfer) associated with carrying $z(i)$ units of (real) money balances in an inflationary environment; that is:

$$
z(i)+T-\frac{\phi}{\phi_{+1}} z(i)=z(i)+\tau(1-\xi(i)) z(i)-(1+\tau) z(i)=-\xi(i) \tau z(i) .
$$

Agents with $\xi<\xi(i)$ obtain only $v(i)+T$. To compute the steady state welfare cost of inflation I use the average value of $V$ across types $\xi$ :

$$
(1-\beta) \Omega(i) \equiv \int_{0}^{\xi(i)}[v(i)+(1-\xi(i)) \tau z(i)] d \xi+\int_{\xi(i)}^{1}(1-\beta) V_{\xi}(i) d \xi .
$$

Note that inflation has a redistributive effect (agents not holding money get a positive net transfer). ${ }^{21}$ However, due to the linearity properties of preferences, this redistribution has no real implications for total average welfare, which is given by:

$$
(1-\beta) \Omega(i)=v(i)+\sigma \frac{\left[1-\xi(i)^{2}\right]}{2} S_{1}(i)
$$

Define now the following alternative measure of welfare where the quantities consumed at the zero-interest-rate equilibrium are multiplied by the fraction $\Delta_{F}$ :

$$
(1-\beta) \Omega_{\Delta_{F}}(0)=v(0)+B \log \left(\Delta_{F}\right)+\sigma \frac{1}{2}(1-\varepsilon) u\left(\Delta_{F} q(0)\right) .
$$

Then, I use as a proxy for the welfare cost of inflation the value of $1-\Delta_{F}^{i}$, where $\Delta_{F}^{i}$ is such that $\Omega_{\Delta_{F}^{i}}(0)=\Omega(i)$. We can interpret this value as the amount of consumption agents would be willing to give up to have the nominal interest rate equal zero (the Friedman rule), rather than $i$. Similarly, I compute $1-\Delta_{0}^{i}$, the amount of consumption agents would be willing to give to move from an economy with nominal interest rate equal to $i$ to one with $3 \%$ nominal interest rate (that is, zero inflation). For the calculations, I will use as the benchmark values of $i$ the average level of the nominal interest rate during the period, $i=0.04$, and a higher value, $i=0.13$, which corresponds to a steady state inflation of $10 \%$. Table 2 show the values of $1-\Delta_{F}^{i}$ and $1-\Delta_{0}^{i}$ for the five different combination of parameters presented in Table 1.

Table 2 also shows the equilibrium values of the proportion of output traded in the decentralized market, $\chi(i)$, and the average mark-up, $\mu(i)$, which can be calculated using the following two

\footnotetext{
${ }^{21}$ One alternative strategy that avoids redistribution is to assume that newly printed money is (lump-sum) transferred only to those agents holding the existing balances. This is the standard approach in overlapping generations models of money (see for example Wallace, 1980). In any case, redistribution is inconsequential for the issues of interest in this paper. For a version of the Lagos-Wright framework where this redistribution associated with monetary policy plays a crucial role, see Williamson (2004).
} 
expressions:

$$
\begin{aligned}
& \chi(i)=\frac{\sigma(1-\xi(i)) q(i)}{Y(i)}, \\
& \mu(i)=(1-\chi(i))+\chi(i) \frac{(1-\xi(i)) \varepsilon u(q(i))}{(1-\xi(i)) q(i)} .
\end{aligned}
$$

The value of $\mu(i)$ is the weighted average of the ratio of price over marginal cost in the centralized market (equal to one) and in the decentralized market. The equilibrium values of $\chi(i)$ and $\mu(i)$ give us a sense of how reasonable the parameters are and also are helpful for comparison with the findings in Lagos and Wright (2003). For example, the value of the equilibrium mark-up tends to be relatively low compared with the value 1.1 usually used in calibration.

Table 2

\begin{tabular}{c|cccc|cccc}
\hline Param. & $\mu(0.04)$ & $\chi(0.04)$ & $1-\Delta_{F}^{0.04}$ & $1-\Delta_{0}^{0.04}$ & $\mu(0.13)$ & $\chi(0.13)$ & $1-\Delta_{F}^{0.13}$ & $1-\Delta_{0}^{0.13}$ \\
\hline 1 & 1.045 & 0.033 & 0.025 & 0.011 & 1.019 & 0.009 & 0.073 & 0.061 \\
2 & 1.029 & 0.018 & 0.022 & 0.009 & 1.012 & 0.004 & 0.064 & 0.052 \\
3 & 1.055 & 0.047 & 0.028 & 0.013 & 1.022 & 0.012 & 0.082 & 0.068 \\
4 & 1.057 & 0.050 & 0.029 & 0.013 & 1.023 & 0.013 & 0.084 & 0.071 \\
5 & 1.028 & 0.014 & 0.018 & 0.008 & 1.012 & 0.003 & 0.055 & 0.046 \\
\hline
\end{tabular}

Note also that the welfare cost of inflation and the mark-up are positively associated with the size of the decentralized sector. The model fits the data best when the decentralized sector is relatively small (less than $5 \%$ of the economy) at the nominal interest rate of $4 \%$. However, in the Lagos-Wright model the size of the decentralized market at $10 \%$ inflation, $\chi(0.13)$, is around $5 \%$, which is much larger that the numbers in Table 2 (around $1 \%$ ).

Overall, the welfare cost of inflation implied by the model in this paper is relatively high (comparing with, for example, Lucas, 2000) but the numbers are in the range of those obtained by Lagos and Wright (2003) in their calibration. The main difference in terms of calibration is that in the Lagos-Wright model the bargaining power of buyers is a free parameter. In my model, sellers have all the bargaining power but the difference in willingness to pay among buyers (indexed by $\varepsilon$ ) is a free parameter. In the Lagos-Wright model, the welfare cost of inflation is higher the lower the bargaining power of buyers (that is, the higher the hold-up problem). When buyers and sellers have the same bargaining power (which implies an average mark-up equal to 1.04) they estimate $1-\Delta_{F}^{0.13}$ to be 0.041 and $1-\Delta_{0}^{0.13}=0.032$. When the bargaining power is calibrated to generate a mark-up equal to 1.1, the bargaining power of buyers decreases to $35 \%$ and the welfare cost estimates increase to 0.068 and 0.046 , respectively. 
Rocheteau and Wright (2003) further study the quantitative implications of the Lagos-Wright model by introducing an extensive margin effect based on the ability of agents to choose whether to be buyers or sellers in the decentralized market. Again, the bargaining power of the buyers is a key parameter in the calibrations and the existence of an extensive margin tends to increase the welfare cost of inflation. In particular, for the lowest level of the buyer's bargaining power that they report $(20 \%)$, the welfare cost estimates are $1-\Delta_{F}^{0.13}=0.101$ and $1-\Delta_{0}^{0.13}=0.074$.

In general, the welfare cost estimates presented in Table 2 are well within the range of estimates that result from the original Lagos-Wright framework. This makes sense. The assumption in this paper is that sellers have all the bargaining power, which would tend to increase sellers' hold-up power and the welfare cost of inflation. However, the presence of private information limits that ability of sellers to exercise hold-up power over buyers and the combination of those two opposing effects brings the welfare estimates to be very close to the ones reported by Lagos and Wright (2003).

\section{CONCLUDING REMARKS}

The economy studied in this paper reduces to the one in Lagos and Wright (2003) when $\varepsilon_{1}=\varepsilon_{2}$. However, since we are assuming that sellers have all the bargaining power, no monetary equilibria with positive nominal interest rates exists in that economy. The reason for this is that the seller can exercise, in full, his hold-up power, depriving the potential buyer of any incentive to carry money into the match. When this is the case, there is no trade (nor consumption) in the decentralized market. The seller would want to commit not to extract all the surplus from future matches to provide incentives for the potential buyer to hold money. However, this commitment is not available to the seller and due to his own ability to extract too much surplus from a potential match, the seller is left with no surplus at all (because to generate any surplus the buyer must be holding some money).

Introducing imperfect information (the case of $\varepsilon_{1} \neq \varepsilon_{2}$ in this paper) limits the ability of the seller to extract surplus from the buyer and hence provides the necessary incentives for the buyer to carry money into the decentralized market. This modification, in turn, translates into some trading in that market and an increase in welfare.

It is clear that one could combine imperfect information with more flexible bargaining rules (like those studied in Lagos and Wright, 2003). To the extent that uncertainty on the buyers' willingness to pay is a realistic feature, this may be an attractive strategy to follow. In this paper, I have shown that aside from being realistic and tractable, imperfect information makes existence of monetary equilibrium a more robust feature of the environment. 


\section{REFERENCES}

1. Camera, Gabriele and Alain Delacroix. "Trade Mechanism Selection in Markets with Frictions," forthcoming in Review of Economic Dynamics (2004).

2. Cho, In-Koo and David M. Kreps. "Signaling Games and Stable Equilibria," Quarterly Journal of Economics 52 (2), (May 1987): 179-221.

3. Curtis, Elisabeth and Randall Wright. "Price Setting, Price Dispersion, and the Value of Money, or The Law of Two Prices," (2003).

4. Faig, Miquel and Belén Jerez. "A Theory of Commerce," forthcoming in Journal of Economic Theory (2003).

5. Goldfeld, Stephen M. and Daniel E. Sichel. "The Demand for Money," in Handbook of Monetary Economics, Benjamin M. Friedman and Frank H. Hahn (eds.), Vol. 1, Elsevier Science, Amsterdam (1990): 299-356.

6. Lagos, Ricardo and Guillaume Rocheteau. "Inflation, Output, and Welfare" forthcoming in International Economic Review (2003).

7. Lagos, Ricardo and Randall Wright. "A Unified Framework for Monetary Theory and Policy Analysis," forthcoming in Journal of Political Economy (2003).

8. Lucas, Robert E. Jr. "Inflation and Welfare," Econometrica 68 (2) (March 2000): 247-274.

9. Maskin, Eric and John Riley. "Monopoly with Incomplete Information," Rand Journal of Economics 15 (2 Summer) (1984): 171-196.

10. Rocheteau, Guillaume and Randall Wright. "Inflation and Welfare in Models with Trading Frictions," in The Economics of Low Inflation, David Altig and Ed Nosal (eds.) (2003).

11. Rocheteau, Guillaume and Randall Wright. "Money in Search Equilibrium, in Competitive Equilibrium, and in Competitive Search Equilibrium," forthcoming in Econometrica (2004).

12. Shi, Shouyong. "A Divisible Search Model of Fiat Money," Econometrica 64 (1) (January 1997): 75-102.

13. Trejos, Alberto and Randall Wright. "Search, Bargaining, Money and Prices," Journal of Political Economy 103 (1995): 118-141.

14. Wallace, Neil. "The Overlapping Generations Model of Fiat Money," in Models of Monetary Economies, John H. Kareken and Neil Wallace (eds.), Minneapolis: Federal Reserve Bank of Minneapolis (1980): 49-82.

15. Williamson, Stephen D. "Search, Limited Participation, and Monetary Policy," (2004).

16. Williamson, Stephen D. and Randall Wright. "Barter and Monetary Exchange Under Private Information," American Economic Review 84 (1) (March 1994): 104-123.

17. Woodford, Michael. "Monetary Policy and Price Level Determinacy in a Cash-in-Advance Economy," Economic Theory 4 (1994): 345-380. 


\section{Appendix 1: Proofs}

This appendix provides all the proof for the lemmas and propositions in the paper.

Lemma 2.1: The solution to problem (1) satisfies:

(1) $\varepsilon_{1} u\left(q_{1}\right)-\phi d_{1}>0$,

(2) $\varepsilon_{1} u\left(q_{1}\right)-\phi d_{1}=\varepsilon_{1} u\left(q_{2}\right)-\phi d_{2}$,

(3) $\varepsilon_{2} u\left(q_{2}\right)-\phi d_{2}=0$, and

(4) $q_{1} \geq q_{2}, d_{1} \geq d_{2}$.

Proof: (1) Combining the inequalities in the constraints of the problem we get $\varepsilon_{1} u\left(q_{1}\right)-\phi d_{1} \geq$ $\varepsilon_{1} u\left(q_{2}\right)-\phi d_{2} \geq \varepsilon_{2} u\left(q_{2}\right)-\phi d_{2} \geq 0$; (2) To prove that this equality holds in the solution, suppose it does not, that is, suppose that $\varepsilon_{1} u\left(q_{1}\right)-\phi d_{1}>\varepsilon_{1} u\left(q_{2}\right)-\phi d_{2}$. Then, the seller, by choosing a smaller $q_{1}$, will increase the value of his objective function and still satisfy all the constraints. In particular, $\varepsilon_{1} u\left(q_{1}\right)-\phi d_{1}>\varepsilon_{1} u\left(q_{2}\right)-\phi d_{2} \geq 0$ we know that for small decreases in $q_{1}$ the participation constraint of subtype 1 buyers will still be satisfied. Also, the incentive constraint for subtype 1 will still be satisfied and the incentive constraint of subtype 2 will actually be relaxed. Hence, a lower $q_{1}$ is feasible and it is better for the seller. Hence the incentive constraint of a subtype 1 agent must be binding in the solution; (3) To prove that the participation constraint of subtype 2 agents must be binding in the solution, suppose not. Suppose the solution has $\varepsilon_{2} u\left(q_{2}\right)-\phi d_{2}>0$. Then, the seller could offer an alternative contract decreasing $q_{1}$ and $q_{2}$ to, say $q_{1}^{\prime}$ and $q_{2}^{\prime}$, and hence increase the value of his objective function. If $q_{1}^{\prime}$ and $q_{2}^{\prime}$ are sufficiently close to the initial $q_{1}$ and $q_{2}$ then the participation constraints would still hold (since under the hypothesis being tested both hold with strict inequality for the initial quantities). Furthermore, if $q_{1}$ and $q_{2}$ are reduced in a manner such that the equality in point (2) of the lemma still holds then we have that $\varepsilon_{2}\left[u\left(q_{1}^{\prime}\right)-u\left(q_{2}^{\prime}\right)\right]<\varepsilon_{1}\left[u\left(q_{1}^{\prime}\right)-u\left(q_{2}^{\prime}\right)\right]=\phi\left(d_{1}-d_{2}\right)$ which implies that the incentive constraint for agents subtype 2 still holds. In other words, reducing the quantities sold to $q_{1}^{\prime}$ and $q_{2}^{\prime}$ is feasible and better for the seller, which shows that the initial $q_{1}$ and $q_{2}$ could not be the solution of the problem; (4) Plugging the equality in point (2) of the lemma in the incentive constraint of subtype 2 agents we get that $\left(\varepsilon_{1}-\varepsilon_{2}\right) u\left(q_{1}\right) \geq\left(\varepsilon_{1}-\varepsilon_{2}\right) u\left(q_{2}\right)$ and hence $q_{1} \geq q_{2}$. Point (2) then implies that $d_{1} \geq d_{2}$ holds.

Remark: When the solution has $q_{1}>q_{2}$ it must hold that $\varepsilon_{2} u\left(q_{1}\right)-\phi d_{1}<0$. To see this, plug the equality in point (2) of the lemma into the equality of point (3) and sum and subtract $\varepsilon_{2} u\left(q_{1}\right)$. Then, we get $\varepsilon_{2} u\left(q_{1}\right)-\phi d_{1}+\left(\varepsilon_{1}-\varepsilon_{2}\right)\left[u\left(q_{1}\right)-u\left(q_{2}\right)\right]=0$ which implies that if $q_{1}>q_{2}$ then $\varepsilon_{2} u\left(q_{1}\right)-\phi d_{1}<0$ must hold. 
Lemma 2.2: The solution $\left(\widehat{q}_{1}, \widehat{q}_{2}, \widehat{z}_{1}\right)$ to problem (2) when the money holdings constraint is non-binding is given by

$$
\begin{aligned}
\widehat{q}_{1} & =q_{1}^{*}, \\
c^{\prime}\left(\widehat{q}_{2}\right) & =\frac{1-p \frac{\varepsilon_{1}}{\varepsilon_{2}}}{1-p} \varepsilon_{2} u^{\prime}\left(\widehat{q}_{2}\right), \\
\widehat{z}_{1} & =\varepsilon_{2} u\left(\widehat{q}_{2}\right)+\varepsilon_{1}\left(u\left(\widehat{q}_{1}\right)-u\left(\widehat{q}_{2}\right)\right) .
\end{aligned}
$$

Proof: Assume the incentive constraint for agent subtype 2 is nonbinding. Then, the first order conditions are:

$$
\begin{aligned}
& q_{1}: p\left[-c^{\prime}\left(q_{1}\right)+\varepsilon_{1} u^{\prime}\left(q_{1}\right)\right]=0, \\
& q_{2}:-p\left(\varepsilon_{1}-\varepsilon_{2}\right) u^{\prime}\left(q_{2}\right)+(1-p)\left[-c^{\prime}\left(q_{2}\right)+\varepsilon_{2} u^{\prime}\left(q_{2}\right)\right]=0 .
\end{aligned}
$$

Reorganizing these expressions we get the first two conditions in the lemma. The third condition results from combining points (2) and (3) of the previous lemma. Finally, since $1-p \frac{\varepsilon_{1}}{\varepsilon_{2}}<1-p$, we have that $\widehat{q}_{2}<q_{2}^{*}<q_{1}^{*}=\widehat{q}_{1}$ and from the remark above it follows that the incentive constraint for agent subtype 2 is indeed not binding.

Lemma 2.3: If $\widehat{z}_{1} \leq z$ then the equilibrium surplus $S_{1}$ is only a function of $p$ (and not a function of $z$ ). Furthermore,

$$
\frac{d S_{1}(p)}{d p}<0
$$

Proof: Expression (A1) defines an implicit function $\widehat{q}_{2}(p)$. It is then easy to check that $\widehat{q}_{2}$ is a decreasing function of $p$ :

$$
\frac{d \widehat{q}_{2}(p)}{d p}=\frac{\left(\varepsilon_{2}-\varepsilon_{1}-p \varepsilon_{1}\right) u^{\prime}\left(\widehat{q}_{2}\right)}{(1-p) c^{\prime \prime}\left(\widehat{q}_{2}\right)-\left(1-p \frac{\varepsilon_{1}}{\varepsilon_{2}}\right) \varepsilon_{2} u^{\prime \prime}\left(\widehat{q}_{2}\right)}<0 .
$$

Using the third equality in Lemma 2.2 we have that $S_{1}(p)=\left(\varepsilon_{1}-\varepsilon_{2}\right) u\left(\widehat{q}_{2}(p)\right)$. Hence:

$$
\frac{d S_{1}(p)}{d p}=\left(\varepsilon_{1}-\varepsilon_{2}\right) u^{\prime}\left(\widehat{q}_{2}(p)\right) \frac{d \widehat{q}_{2}(p)}{d p}<0
$$

Remark: The other endogenous variables' comparative statics with respect to $p$ are:

$$
\frac{d \widehat{z}_{1}}{d p}=\left(\varepsilon_{2}-\varepsilon_{1}\right) u^{\prime}\left(\widehat{q}_{2}\right) \frac{d \widehat{q}_{2}(p)}{d p}>0,
$$


and

$$
\frac{d \widehat{z}_{2}}{d p}=\varepsilon_{2} u^{\prime}\left(\widehat{q}_{2}\right) \frac{d \widehat{q}_{2}(p)}{d p}<0
$$

Lemma 2.4: When $\bar{z}_{2}<\bar{z}_{1}=z<\widehat{z}_{1}$, the solution to problem (2), $\left(\bar{q}_{1}, \bar{q}_{2}, \bar{z}_{1}, \bar{z}_{2}\right)$, is a function of $p$ and $z$ and satisfies:

(1) $\widehat{q}_{2}(p) \leq \bar{q}_{2}(z, p)<q_{2}^{*}$,

(2) $\bar{q}_{1}(z, p)<q_{1}^{*}$, and

(3) $\frac{d \bar{q}_{1}}{d p}<0, \frac{d \bar{q}_{1}}{d z}>0, \frac{d \bar{q}_{2}}{d p}<0, \frac{d \bar{q}_{2}}{d z}<0$.

Proof: From the first order conditions of problem (2) we have that $\left(\bar{q}_{1}, \bar{q}_{2}\right)$ must solve the following system of equations:

$$
\begin{aligned}
f\left(\bar{q}_{2}, p\right) \varepsilon_{1} u^{\prime}\left(\bar{q}_{1}\right) & =p c^{\prime}\left(\bar{q}_{1}\right) \\
\varepsilon_{1} u\left(\bar{q}_{1}\right)-z & =\left(\varepsilon_{1}-\varepsilon_{2}\right) u\left(\bar{q}_{2}\right) \\
\bar{q}_{1} & \geq \bar{q}_{2}
\end{aligned}
$$

where $f\left(q_{2}, p\right) \equiv(1-p)\left[\varepsilon_{2} u^{\prime}\left(q_{2}\right)-c^{\prime}\left(q_{2}\right)\right] /\left(\varepsilon_{1}-\varepsilon_{2}\right) u^{\prime}\left(q_{2}\right)$. Since from the first equation $f\left(\bar{q}_{2}, p\right)=$ $p c^{\prime}\left(\bar{q}_{1}\right) / \varepsilon_{1} u^{\prime}\left(\bar{q}_{1}\right)>0$ we have that by the definition of $f\left(\bar{q}_{2}, p\right)$ it must be the case that $\varepsilon_{2} u^{\prime}\left(\bar{q}_{2}\right)-$ $c^{\prime}\left(\bar{q}_{2}\right)>0$ which in turn implies that $\bar{q}_{2}(z, p)<q_{2}^{*}$ must hold. From the first order conditions, and specifically the complimentary slackness condition for $z_{1} \leq z$, we have that when this constraint is binding $f\left(\bar{q}_{2}, p\right)<p$. Hence $\bar{q}_{1}<q_{1}^{*}$. Also, since $f\left(\widehat{q}_{2}, p\right)=p$ and $f$ is decreasing in $q_{2}$ it holds that $\widehat{q}_{2} \leq \bar{q}_{2}$. To proof point (3) of the lemma define the following two functions

$$
\begin{aligned}
& G\left(\bar{q}_{1}, \bar{q}_{2}, p\right)=f\left(\bar{q}_{2}, p\right) \varepsilon_{1} u^{\prime}\left(\bar{q}_{1}\right)-p c^{\prime}\left(\bar{q}_{1}\right) \equiv 0, \\
& H\left(\bar{q}_{1}, \bar{q}_{2}, z\right)=\varepsilon_{1} u\left(\bar{q}_{1}\right)-z-\left(\varepsilon_{1}-\varepsilon_{2}\right) u\left(\bar{q}_{2}\right) \equiv 0 .
\end{aligned}
$$

Also let $G_{i}$ and $H_{i}$ be the partial derivatives of the functions $G$ and $H$ with respect to the $i t h$ argument. Then, the signs for the comparative statics can be found by solving the following system of equations

$$
\left[\begin{array}{ll}
G_{1} & G_{2} \\
H_{1} & H_{2}
\end{array}\right]\left[\begin{array}{cc}
\frac{d \bar{q}_{1}}{d p} & \frac{d \bar{q}_{1}}{d z} \\
\frac{d \bar{q}_{2}}{d p} & \frac{d \bar{q}_{2}}{d z}
\end{array}\right]=\left[\begin{array}{cc}
-G_{3} & 0 \\
0 & 1
\end{array}\right] .
$$


COROllary 2.1: The surplus from trade of subtype 1 buyers is $S_{1}(z, p) \geq S_{1}(p)$, with equality when $z=\widehat{z}_{1}$. Furthermore, we have that:

$$
\frac{d S_{1}(z, p)}{d p}<0, \quad \frac{d S_{1}(z, p)}{d z}<0
$$

Proof: Note that in equilibrium $S_{1}(z, p) \equiv \varepsilon_{1} u\left(\bar{q}_{1}(z, p)\right)-z=\left(\varepsilon_{1}-\varepsilon_{2}\right) u\left(\bar{q}_{2}(z, p)\right)$. Hence we have that

$$
\frac{d S_{1}(z, p)}{d p}=\varepsilon_{1} u^{\prime}\left(\bar{q}_{1}\right) \frac{d \bar{q}_{1}}{d p}<0
$$

and

$$
\frac{d S_{1}(z, p)}{d z}=\left(\varepsilon_{1}-\varepsilon_{2}\right) u^{\prime}\left(\bar{q}_{2}\right) \frac{d \bar{q}_{2}}{d z}<0 .
$$

Since $\bar{q}_{2} \geq \widehat{q}_{2}$ and $S_{1}(z, p)$ is increasing in $\bar{q}_{2}$ (and equal to $S_{1}(p)$ when $\bar{q}_{2}=\widehat{q}_{2}$ ) we have that $S_{1}(z, p) \geq S_{1}(p)$.

Remark: We defined $\overline{\bar{z}}$ as the value of $z$ below which the subtype 2 agents are cash constrained. Since when $z=\overline{\bar{z}}$ the cash constraint is just binding we still have that $G\left(\bar{q}_{1}, \bar{q}_{2}, p\right)=0$ when $z=\overline{\bar{z}}$. We know that for values of $z \leq \overline{\bar{z}}$ the subtype 1 agents also spend all of their money. Hence, we have that $z_{1}=z_{2}=z$. But then, it must be that $q_{1}=q_{2}=q$. Define $\overline{\bar{q}}$ to be the value of $q$ that satisfies $G(q, q, p)=0$. It is easy to check that $\overline{\bar{q}}$ satisfies

$$
c^{\prime}(\overline{\bar{q}})=\frac{1-p}{1-p \frac{\varepsilon_{2}}{\varepsilon_{1}}} \varepsilon_{2} u^{\prime}(\overline{\bar{q}})
$$

We can then use $\overline{\bar{q}}$ to obtain the value of $\overline{\bar{z}}$ since it must be the case that $\overline{\bar{z}}=\varepsilon_{2} u(\overline{\bar{q}})$. Since it is clear from the equation above that $\overline{\bar{q}}$ is a decreasing function of $p$, then $\overline{\bar{z}}$ is also a decreasing function of $p$.

Proposition 2.2: A sequence $\left\{\xi_{t}^{s}, p_{t}, q_{t}, z_{t}(\xi), \phi_{t}\right\}_{t=0}^{\infty}$ satisfying the following equations describes a monetary (sequential) perfect foresight equilibrium for this economy:

$$
\begin{aligned}
z_{t}(\xi) & =\overline{\bar{z}}\left(p_{t}\right) \text { for all } \xi \geq \xi_{t}^{s}=\frac{\varepsilon_{2}}{\sigma\left(\varepsilon_{1}-\varepsilon_{2}\right)}\left(\frac{\pi_{t+1}}{\beta}-1\right), \\
z_{t}(\xi) & =0 \text { for all } \xi<\xi_{t}^{s} \\
p_{t} & =\frac{1+\xi_{t-1}^{s}}{2} \\
q_{t} & =\overline{\bar{q}}\left(p_{t}\right) \text { for all } \xi \geq \xi_{t}^{s}, \text { and } \\
\phi_{t} & =\overline{\bar{z}}\left(p_{t}\right)\left(1-\xi_{t-1}^{s}\right) / M_{t},
\end{aligned}
$$

where $\pi_{t+1}=\phi_{t} / \phi_{t+1}$ and $\xi_{t}^{s} \in[0,1]$ for all $t$. 
Proof: The essential part of the proof is to show that the proposed beliefs sustain a sequential equilibrium. I will also show that such beliefs satisfy reasonable criteria in the off-equilibrium path. Since the focus is on the intra-period equilibrium, I will drop the time index to simplify notation. Start with the following conjectured beliefs: $p(z)=p^{*}$ for all $z$. These beliefs justify the behavior of the seller on and off the equilibrium path such that the implied surplus function for the buyer is given by expression (3). Then, all agents with $\xi \geq \xi^{s}$ will choose $z(\xi)=\overline{\bar{z}}\left(p^{*}\right)$ and all agents with $\xi<\xi^{s}$ will choose $z(\xi)=0$. The concept of sequential equilibrium does not impose any restriction on beliefs $p(z)$ for all off-equilibrium actions $z \neq \overline{\bar{z}}\left(p^{*}\right)$. For $z=\overline{\bar{z}}\left(p^{*}\right)$ however, we have that $p(z)$ should be the result of applying Bayes' rule, which in this case implies that $p\left(\overline{\bar{z}}\left(p^{*}\right)\right)=\left(1+\xi^{s}\right) / 2$. Then, the belief $p(z)=p^{*}=\left(1+\xi^{s}\right) / 2$ for all $z$ will sustain a sequential equilibrium.

Next, I show that these beliefs are also reasonable in off-equilibrium situations (see, for example, Cho and Kreps, 1987). First consider deviations for the agents holding no real balances in equilibrium. Since for all $\xi<\xi^{s}$ the following inequality holds:

$$
\begin{aligned}
-(\pi-\beta) z+\beta \sigma \xi S_{1}(z, p) & =-(\pi-\beta) z+\beta \sigma \xi \frac{\varepsilon_{1}-\varepsilon_{2}}{\varepsilon_{2}} z_{2}(p) \\
& \leq\left[-(\pi-\beta)+\beta \sigma \xi \frac{\varepsilon_{1}-\varepsilon_{2}}{\varepsilon_{2}}\right] z<0,
\end{aligned}
$$

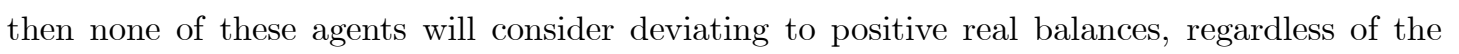
beliefs of the seller.

Now consider the case of deviations by agents with $\xi \geq \xi^{s}$. Let us start with deviations to values of real balances that are lower than the equilibrium level; that is, $z<\overline{\bar{z}}\left(p^{*}\right)$. Note that for all $\xi \geq \xi^{s}$ we have that $-(\pi-\beta) z+\beta \sigma \xi S_{1}(z, p) \leq-(\pi-\beta) \overline{\bar{z}}\left(p^{*}\right)+\beta \sigma \xi S_{1}\left(\overline{\bar{z}}\left(p^{*}\right), p^{*}\right)$ for all $z \leq \overline{\bar{z}}\left(p^{*}\right)$ and all $p$. To see this, note that

$$
\begin{aligned}
-(\pi-\beta) z+\beta \sigma \xi S_{1}(z, p) & =-(\pi-\beta) z+\beta \sigma \xi \frac{\varepsilon_{1}-\varepsilon_{2}}{\varepsilon_{2}} z_{2}(p) \\
& \leq\left[-(\pi-\beta)+\beta \sigma \xi \frac{\varepsilon_{1}-\varepsilon_{2}}{\varepsilon_{2}}\right] z \\
& \leq\left[-(\pi-\beta)+\beta \sigma \xi \frac{\varepsilon_{1}-\varepsilon_{2}}{\varepsilon_{2}}\right] \overline{\bar{z}}\left(p^{*}\right) \\
& =-(\pi-\beta) \overline{\bar{z}}+\beta \sigma \xi S_{1}(\overline{\bar{z}}, p) .
\end{aligned}
$$

Then, no agent with $\xi \geq \xi^{s}$ will consider lowering her real balances. In other words, this potential deviation is not relevant no matter what the off-equilibrium beliefs of the seller are.

Now consider the case of deviations to higher values of $z$; that is, $z>\overline{\bar{z}}\left(p^{*}\right)$. If $p(z)>p^{*}$ then $S_{1}(z, p(z)) \leq S_{1}\left(z, p^{*}\right) \leq S_{1}\left(\overline{\bar{z}}\left(p^{*}\right), p^{*}\right)$ and no agent would pursue this deviation (carrying 
additional units of money is costly and does not produce any extra surplus). If $p(z)<p^{*}$, things are more complicated. In particular, the surplus may or may not increase. Assume it does (otherwise, the same logic as before tells us that no agent follows that deviation). Furthermore, assume that

$$
-(\pi-\beta) z+\beta \sigma \xi S_{1}(z, p(z))>-(\pi-\beta) \overline{\bar{z}}\left(p^{*}\right)+\beta \sigma \xi S_{1}\left(\overline{\bar{z}}\left(p^{*}\right), p^{*}\right)
$$

for some type $\xi$. Then, there exists $\bar{\xi}$ such that the inequality holds for all $\xi>\bar{\xi}$. It is easy to see that $\bar{\xi}$ must be greater than or equal to $\xi^{s}$. This is because

$$
-(\pi-\beta) z+\beta \sigma \xi^{s} S_{1}(z, p(z)) \leq-(\pi-\beta) z+\beta \sigma \xi^{s} \frac{\varepsilon_{1}-\varepsilon_{2}}{\varepsilon_{2}} z=0,
$$

and $-(\pi-\beta) \overline{\bar{z}}\left(p^{*}\right)+\beta \sigma \xi^{s} S_{1}\left(\overline{\bar{z}}\left(p^{*}\right), p^{*}\right)=0$. Then, there are two possibilities: (1) If $\bar{\xi}=\xi^{s}$ then any agent with $\xi>\xi^{s}$ would want to deviate to the higher value of $z$. In this case, reasonable beliefs would have $p(z)=p^{*}$ which contradicts the starting hypothesis $p(z)<p^{*}$. (2) If $\bar{\xi}>\xi^{s}$ then only those buyers with $\xi>\bar{\xi}$ would want to deviate. But then the belief $p(z)$ should be even higher than $p^{*}$ since only agents with relatively high values of $\xi$ (and, in particular, strictly higher than $\xi^{s}$ ) will be the potential deviators. This again is a contradiction. Finally, we could consider more complicated off-equilibrium beliefs that could potentially justify a deviation. Suppose, for example, that there are several different values of $z>\overline{\bar{z}}\left(p^{*}\right)$ that agents could consider deviating to. In this case, if some values of $z$ attract specially those agents that have $\xi$ close to $\xi^{s}$, it could be reasonable to assign to those values of $z$ a belief $p(z)$ lower than $p^{*}$. However, for this to make sense, there must be another value of $z>\bar{z}\left(p^{*}\right)$ that attracts agents with high $\xi$. Then, for such a value of $z$, it must be the case that reasonable beliefs satisfy $p(z)>p^{*}$ which in turn tell us that those agents would not be willing to take such a deviation. In fact, a similar argument shows that there is no sequential equilibrium with complete sorting of types $\xi$.

Remark: There is no equilibrium with complete sorting of types $\xi$ for $\xi \geq \xi^{s}$. To see this, take an arbitrary belief function $p(z)$. The surplus for a buyer with $\varepsilon_{i}=\varepsilon_{1}$ is now given by $S_{1}(z, p(z)) \equiv S(z)$ with derivative given by

$$
\frac{d S}{d z}=\frac{d S_{1}}{d z}+\frac{d S_{1}}{d p} \frac{d p}{d z}
$$

Note that if $d S_{1} / d z>0$ then $d S_{1} / d p=0$ and $d^{2} S_{1} /(d z)^{2}=0$. Also if $d S_{1} / d p<0$ then $d S_{1} / d z<0$ (Note that $d S_{1} / d p$ is never positive). For any belief function there exists a level of real money holdings $z^{U}$ such that for all $z>z^{U}$ we have that $S(z)$ is constant independent of $z$ (in fact, we know that $\left.z^{U} \leq \varepsilon_{1} u\left(q_{1}^{*}\right)\right)$. 
Then the agent's real money holdings are given by the solution to the following problem

$$
\max _{z \in\left[0, z^{U}\right]}-(\pi-\beta) z+\beta \sigma \xi S(z)
$$

Let $z^{*}(\xi)$ be the solution to problem (A2). For a complete sorting of types to be an equilibrium the surplus function $S(z)$ must be increasing and strictly concave. Note then that $z^{*}(\xi)$ would be increasing. But in equilibrium it should be the case that $p\left(z^{*}(\xi)\right)=\xi$. Then, the only belief functions consistent with equilibrium are those that have $d p / d z>0$. But for $S(z)$ to be strictly concave it must be that $d S_{1} / d z<0$ and hence $d S / d z<0$ which contradicts the requirement that $S(z)$ be increasing. Note that the key to this logic lies in the fact that we require that the belief function satisfy $p\left(z^{*}(\xi)\right)=\xi$, which is Bayes' rule in the conjectured equilibrium path.

Lemma 2.6: In the set of constant-inflation monetary equilibria indexed by $\tau>\beta-1$ we have that:

$$
\text { (i) } \frac{\partial \xi_{\tau}}{\partial \tau}>0, \quad(i i) \frac{\partial p_{\tau}}{\partial \tau}>0, \text { and } \quad \text { (iii) } \frac{\partial q_{\tau}}{\partial \tau}<0 .
$$

Proof: Note that for a monetary equilibrium to exist it must be the case that $\xi_{\tau}<1$. This condition determines an upper bound on the values of $\tau$ that are compatible with monetary equilibrium. For values of $\tau$ below this upper bound, we have that in a constant-inflation monetary equilibria $\xi_{t}^{s}$ and $p_{t}$ are constants. Hence

$$
\phi_{t} M_{t}=\overline{\bar{z}}(p)\left(1-\xi^{s}\right)=\phi_{t+1} M_{t+1}=\phi_{t+1}(1+\tau) M_{t}
$$

which implies that $\pi_{t}=\phi_{t} / \phi_{t+1}=(1+\tau)$ for all $t$. Then, the set of constant-inflation monetary equilibria is described by the following set of equations:

$$
\begin{aligned}
\xi_{\tau} & =\frac{\varepsilon_{2}}{\sigma\left(\varepsilon_{1}-\varepsilon_{2}\right)}\left(\frac{1+\tau}{\beta}-1\right), \\
p_{\tau} & =\frac{1+\xi_{\tau}}{2} \\
c^{\prime}\left(q_{\tau}\right) & =\frac{1-p_{\tau}}{1-p_{\tau} \frac{\varepsilon_{2}}{\varepsilon_{1}}} \varepsilon_{2} u^{\prime}\left(q_{\tau}\right) .
\end{aligned}
$$

The comparative statics with respect to $\tau$ are straightforward. 